\title{
O USO DE TECNOLOGIAS MÓVEIS NO ENSINO DE CIÊNCIAS: UMA EXPERIÊNCIA SOBRE O ESTUDO DOS ECOSSISTEMAS COSTEIROS DA MATA ATLÂNTICA SUL CAPIXABA
}

\section{EL UTILIZAR LA TELEFONÍA MÓVIL EN LA EDUCACIÓN CIENTÍFICA: UNA EXPERIENCIA EN EL ESTUDIO DE ECOSISTEMA COSTERO DEL ATLÁNTICO SUR CAPIXABA}

\author{
THE USE OF MOBILE TECHNOLOGIES IN SCIENCE TEACHING: AN \\ EXPERIENCE ON THE COASTAL ECOSYSTEM STUDY OF THE SOUTH \\ MATA ATLÂNTICA CAPIXABA
}

\author{
Raíza Carla Mattos SANTANA ${ }^{1}$ \\ Luciane da Silva Lima VIEIRA $^{1}$ \\ Guilherme Augusto Maciel RIBEIRO ${ }^{1}$ \\ Danielli Veiga Carneiro SONDERMANN ${ }^{2}$ \\ Isaura Alcina Martins NOBRE ${ }^{2}$
}

RESUMO: O uso das tecnologias de informação e comunicação (TICs) é objeto de discussão por grande parte dos educadores brasileiros. Se por um lado é reconhecido como potencial recurso em favor dos processos ensino-aprendizagem, por outro, desperta grandes polêmicas no contexto escolar. Dessa forma, a partir de uma sequência didática fundamentada nos Três Momentos Pedagógicos de Delizoikov et al. (2002), o presente trabalho teve por objetivo promover uma discussão sobre o uso das tecnologias móveis no estudo dos ecossistemas costeiros de Mata Atlântica com alunos de uma escola pública municipal de Marataízes/ ES. Como fonte de obtenção de dados, realizou-se pesquisas bibliográficas em fontes de papel e virtuais, por intermédio smartphones. Além disso, promoveu-se uma aula de campo nos ecossistemas costeiros de Mata Atlântica situados na área geoescolar, ocasião em que as tecnologias móveis atuaram como instrumentos para identificação da fauna e flora mediante o uso de aplicativo, além de servir para o registro audiovisual que, posteriormente, foi transformado em objetos educativos que foram expostos para a comunidade escolar. Foi diagnosticado o grande interesse dos estudantes em utilizar as tecnologias móveis em situações de aprendizagem, o que sinaliza para a importância do uso das TICs como ferramentas educacionais, reforçando a potencial articulação dos recursos tecnológicos nos processos de ensino e aprendizagem em Ciências.

PALAVRAS-CHAVE: Aprendizagem móvel. Ensino de Ciências. Ecossistemas costeiros. Educação ambiental.

RESUMEN: El uso de tecnologías de la información y la comunicación (TIC) es objeto de discusión durante gran parte de los educadores brasileños. Si por un lado se reconoce como un recurso potencial en favor de la enseñanza-aprendizaje, por el otro, suscita gran controversia en el contexto escolar. Por lo tanto, a partir de una secuencia didáctica basada en los tres momentos pedagógicos de Delizoikov et al (2002), este

\footnotetext{
${ }^{1}$ Mestrandos em Ensino de Ciências e Matemática pelo Instituto Federal do Espírito Santo, Campus Vitória/ ES.

2 Doutoras em Educação. Professoras do Programa de Pós-graduação Strictu Sensu em Ensino de Ciências e Matemática do Instituto Federal do Espírito Santo, Campus Vitória/ ES.
} 
estudio tuvo como objetivo promover un debate sobre el uso de las tecnologías móviles en el estudio de los ecosistemas costeros de la Mata Atlántica con los estudiantes de una escuela públicos municipales Marataízes / ES. Como fuente de recopilación de datos, hubo bibliográficas fuentes de papel de investigación y virtual, a través de los teléfonos inteligentes. Además, promovió un campo de clase en los ecosistemas costeros del Bosque Atlántico situadas en la zona geoescolar, en el que las tecnologías móviles han actuado como herramientas para la fauna y la flora de identificación por el uso de las aplicaciones, además de servir para el registro audiovisual que se transformó más tarde en objetos educativos que fueron expuestos a la comunidad escolar. el gran interés de los estudiantes a utilizar las tecnologías móviles en situaciones de aprendizaje fue diagnosticada, que apunta a la importancia del uso de las TIC como herramientas educativas, reforzando el vínculo potencial de los recursos tecnológicos en la enseñanza y el aprendizaje de la ciencia.

PALAVRAS CLAVE: Aprendizaje móvil. Enseñanza de las Ciencias. Los ecosistemas costeros. Educación ambiental. Espacios de educación no formal

ABSTRACT: The use of information and communication technologies (ITC's) is the subject of discussion by most Brazilian educators. If it is recognized as a potential resource in favor of the teaching-learning processes, and it arouses great controversy in the school context. This way, the objective of this work was to promote a discussion about the use of mobile technologies in the study of the coastal ecosystems of Mata Atlântica with students of a public school of Marataizes / ES. As a source of data collection, bibliographical research was carried out in paper and virtual sources, through smartphones. In addition, a field lesson was organized in the coastal ecosystems of the Mata Atlantica located in the geo-school area, at which time mobile technologies acted as instruments to identify fauna and flora through the use of an application, in addition to serving the audiovisual record, later it was transformed into educational objects that were exposed to the school community. It was of great interes of the interest of the students to use mobile technologies in learning situations, which indicates the importance of the use of ICTs as educational tools, reinforcing the potential articulation of technological resources in the processes of teaching and learning in Sciences.

KEYWORDS: Mobile learning. Science teaching. Coastal ecosystems. Environmental education. Non-formal education spaces.

\section{Introdução}

O desenvolvimento da ciência trouxe novas tecnologias e como resultado um conhecimento científico diferenciado e emancipado do senso comum, exigindo novas práticas de ensino que promovam novos conhecimentos que sejam capazes de se articular com melhorias na qualidade de vida da sociedade, instigando nossa inteligência para o entendimento e compreensão do mundo que nos rodeia.

Torna-se necessário que os novos conhecimentos também nos permitam formular novas hipóteses, analisar nossas ações, identificar possíveis erros e suscitar 
novos questionamentos, sempre com uma postura investigativa e dinâmica com espírito de curiosidade e o anseio por novas descobertas.

Nesse contexto, é importante e necessário que a escola consiga conjecturar em suas práticas novas estratégias e esteja atenta as mudanças que as novas gerações adquiriram e trazem consigo desde sua alfabetização e até mesmo antes desta, promovendo a necessidade de trabalhar de forma contextualizada com os problemas científicos, capacitando o sujeito para o pleno exercício da cidadania a partir da compreensão das Ciências e de seus impactos, com apropriação do conhecimento científico e desenvolvimento intelectual das novas gerações.

É importante que a escola como instituição e os docentes como principais mediadores do conhecimento científico e o cotidiano das novas gerações de alunos estejam atentos ao descompasso presente entre as ações realizadas no ambiente escolar e o mundo exterior desse aluno, repensando seus recursos didáticos e sua organização como instituição de ensino. Sabendo de todas as limitações da escola e da formação de seus professores, devemos buscar alternativas para que o conhecimento chegue aos alunos de forma moderna e contemporânea, despertando maior interesse nas aulas de Ciências, ressaltando que a informação faz parte de uma etapa de desenvolvimento do aluno e esse deverá ser capaz de trilhar autonomamente os caminhos que o levem a descobrir novas estratégias que o levem a adquirir capacidade de identificar, selecionar e separar o que é mais relevante em seus aprendizado e o que o torne mais capaz de exercer sua cidadania.

\section{O uso das tecnologias móveis no ensino de Ciências}

O quantitativo de instrumentos e apetrechos tecnológicos que fazem parte do cotidiano da coletividade expressam a relação intrínseca e irreversível entre sociedade e tecnologia. É notória a influência que tais instrumentos exercem nas atitudes e hábitos dos adolescentes e jovens, visto que a grande maioria deles possuem celulares e fazem uso frequente de suas diversas funções. Esse público é o mesmo que constitui o grupo discente das escolas, pois já nasceram conectados ou cresceram imersos no mundo digital. A eles é dada a denominação de 'nativos digitais', em contraposição às gerações anteriores, as quais os professores fazem parte, designada de 'imigrantes digitais', isto é, aqueles que precisam aprender a conviver em meio a diferentes inovações tecnológicas (GROSSI; FERNANDES, 2014). 
Compreende-se como tecnologias móveis, dispositivos que compartilham as características centrais dos seus pares atuais, são digitais, portáveis, individuais, multimídia, conectam-se à internet e facilitam tarefas relacionadas com a comunicação (UNESCO, 2014a). São exemplos: telefones celulares básicos, leitores eletrônicos, smartphones e tablets.

Esse recurso, no âmbito educacional, atua como ferramenta pedagógica que, segundo Lucena (2016, p. 287) "potencializa a produção de saberes construídos de forma coletiva e colaborativa, utilizando as redes sociodigitais". Assim, cabe ressaltar que

as tecnologias por si só não tem nenhuma força de transformação dos contextos educacionais. A simples inserção delas na educação, sem uma proposta didático-pedagógica consistente, coerente e um planejamento alinhado com as necessidades dos alunos, não é um caminho recomendado para se explorar suas potencialidades e possibilitar o desenvolvimento de práticas educacionais diferenciadas. Inúmeras são as potencialidades, mas as tecnologias apenas podem ganhar vida no contexto educacional se as propostas metodológicas forem suficientemente abertas, criativas e focadas no sujeito aprendiz (COSTA E SILVA; CORDEIRO; SILVA, 2014, p. 59).

Muitos estudos vêm sendo desenvolvidos nesse eixo temático, contudo, observa-se que a utilização dos dispositivos ainda está restrita ao espaço físico de uma sala de aula (ALMEIDA; ARAÚJO JÚNIOR, 2003, p. 32). Sabe-se da importância de inserção desses instrumentos no contexto escolar, todavia, a mobilidade, característica própria desses recursos, permite aperfeiçoar também o seu uso em ambientes fora das paredes da sala de aula. Fica evidente a necessidade de encorajar o processo de aprendizagem para além dos parâmetros tradicionais, propiciando apropriação de conhecimentos em ambientes extraescolares.

A partir daí, é pertinente fazer a seguinte indagação: Como promover práticas pedagógicas para além do contexto formal, aliadas ao uso do celular como instrumento auxiliar no processo de ensino e aprendizagem, com ênfase no desenvolvimento de postura ativa, crítica e colaborativa dos estudantes frente a questões sociocientíficas?

Um meio plausível para tal problemática é empregar as variadas funções do celular em uma prática pedagógica desenvolvida em espaços de educação não-formal, sejam eles Institucionalizados (museus, zoológicos, jardins botânicos, etc.) ou Não Institucionalizados (praças públicas, áreas verdes, lagos e igarapés, praias, entre outros). Conceitos esses baseados em Jacobucci (2008) que sugere:

$\mathrm{Na}$ categoria Instituições, podem ser incluídos os espaços que são regulamentados e que possuem equipe técnica responsável pelas atividades 
executadas, sendo os Museus, Centros de Ciências, Parques Ecológicos, Parques Zoobotânicos, Jardins Botânicos, Planetários, Institutos de Pesquisa, Aquários, Zoológicos, entre outros. Já os ambientes naturais e urbanos que não dispõem de estruturação institucional, mas onde é possível adotar práticas educativas, englobam as categorias Não Instituições. Nessa categoria podem ser incluídos teatro, parque, casa, rua, praça, terreno, cinema, praia, caverna, rio, lagoa, campo de futebol, dentre outros inúmeros espaços. (JACOBUCCI, 2008, p.56-57).

Com base no exposto, consideramos os ambientes de restinga e de mangue estudados nesta proposta como espaços de educação não formal, não institucionalizados, uma vez que não dispõem de estruturação institucional, mas é possível a prática de ações educativas mediante a intencionalidade, e um multidimensional, crítico e transformador do professor.

Superar o tradicional método de aula expositiva em atividades realizadas em espaços não formais se baseia na responsabilidade de engendrar situações impregnadas de intencionalidade e de olhar crítico em função de desenvolver uma educação para a cidadania. Essas intencionalidades e proposições comungam com os pensamentos de Gonh (2010) sobre educação não formal, que visa capacitar o aluno a se tornar cidadão do mundo, e no mundo, pelo fato de ela abrir "[...] janelas de conhecimento sobre o mundo que circunda os indivíduos e suas relações sociais [...]” (GONH 2010, p.19).

As atividades desenvolvidas em ambientes naturais atraem e motivam os estudantes, pois rompem com a uniformidade das salas de aulas e promovem múltiplas relações entre as áreas do conhecimento, em oposição à retalhamento dos conteúdos, visto que a natureza é genuinamente interdisciplinar. Além de promover uma mudança de valores e uma postura em relação ao meio ambiente, a saída de campo é uma metodologia que auxilia na construção dos conhecimentos científicos, principalmente aqueles relacionados à ecologia (SENICIATO; CAVASSAN, 2004). Além disso, as impressões e percepções experimentadas em um ambiente natural, dificilmente podem ser apreendidas e aprendidas em sala de aula.

A utilização do celular como instrumento nessa abordagem não se restringe à realização apenas de aula de campo, mas também perpassa a sua preparação e posterior avaliação, uma vez que esta se baseia em uma intervenção pedagógica direcionada e intencional para a formação cidadã e demanda a realização de três etapas distintas, fundamentais e indispensáveis, o pré campo, o campo e o pós campo como postula SILVEIRA; CRESTANI; FRICK (2014). 
levantadas informações gerais sobre a área de estudo, passadas instruções aos alunos e discutidas algumas questões gerais sobre o local a ser percorrido. $\mathrm{O}$ campo propriamente dito é a realização da atividade de acordo com os objetivos anteriormente propostos. Já o pós-campo é momento de avaliação da atividade, podendo ser aproveitado para comentários adicionais, considerações posteriores e discussões sobre particularidades observadas durante atividade (SILVEIRA; CRESTANI; FRICK, 2014, p. 131).

Compreendemos que em aulas de campo o planejamento é fator determinante para a sua prática agregada a utilização dos recursos e aplicativos disponíveis nos aparelhos móveis de celular. Assim, cabe ao professor, primeiramente, durante o pré campo, conscientizar e amadurecer a percepção dos discentes para o uso do celular como uma ferramenta educativa (evitando possíveis distrações) e trabalhar previamente com a turma, em forma de oficinas, por exemplo, o manejo dos recursos disponíveis no aparelho para a prática extraescolar. A partir daí, pode-se nortear o olhar dos alunos para as possíveis observações in loco e qual a função do celular na atividade, por meio de roteiros semiestruturados além da mediação docente. Posteriormente, no local próprio da aula de campo, o ideal é que sejam feitos grupos de investigação, que possam de forma colaborativa criar hipóteses para possíveis indagações, registrar anotações, fazer fotografias, realizar entrevistas, enfim, a problemática principal da relação entre o ambiente, o conteúdo científico e o contexto social deve ser trabalhado e construído pelos próprios alunos. Por fim, no pós campo, na volta ao ambiente escolar, é necessário que seja feito um feedback da vivência em campo e que os alunos possam exteriorizar, de maneira oral e/ou escrita, as considerações e conclusões a partir das observações realizadas e da utilização das tecnologias móveis.

O professor é fundamental para assegurar que tal abordagem seja desenvolvida em consonância com o conteúdo tratado e as implicações sociais, "pois além de planejar toda a atividade, ele vai trabalhar como um mediador entre os conhecimentos existentes nos ambientes visitados e o estudante" (OLIVEIRA; CORREIA, 2013, p. 166).

\section{Os Três Momentos Pedagógicos e o diálogo com o estudo sobre os ecossistemas costeiros da Mata Atlântica sul capixaba}

Ancorada em uma pesquisa qualitativa baseada em Flick (2009) e assumindo o caráter exploratório descritivo proposto por Gil (1999), foi proposto um estudo de cunho pedagógico sobre os ecossistemas costeiros da Mata Atlântica (restinga e manguezal) por alunos do $7^{\circ}$ ano do Ensino Fundamental da Escola Municipal de 
Ensino Fundamental “José Marcelino”, situada no município de Marataízes, litoral sul do estado do Espírito Santo, totalizando 64 alunos, sujeitos dessa pesquisa. É interessante destacar que tais ecossistemas estão circunscritos no entorno da comunidade escolar, sendo parte integrante das propostas pedagógicas da instituição de ensino, assim como configura o local de moradia e exploração econômica pelos sujeitos dessa pesquisa e por seus familiares.

O estudo abordado assumiu aspecto colaborativo, sendo estruturado a partir de uma sequência didática fundamentada nos Três Momentos Pedagógicos propostos por Delizoikov et al. (2002). Na primeira de suas etapas, os autores propõem a Problematização Inicial, momento em que são procedidas investigações inferenciais durante uma aula dialogada sobre os conhecimentos tácitos dos estudantes sobre a fauna e a flora da região estudada, assim como seus aspectos sociais, ambientais, econômicos e culturais. O diagnóstico evidenciou que, mesmo sendo moradores e/ou freqüentadores desses ambientes naturais, ainda era insuficiente o conhecimento científico sobre os aspectos ambientais, biológicos, inclusive sociais, econômicos e culturais desses ecossistemas costeiros, fato que motivou o desenvolvimento das ações educativas subseqüentes.

$\mathrm{Na}$ etapa seguinte, designada pelos autores como Organização do Conhecimento, os alunos foram desafiados a buscar informações sobre a composição ambiental e biológica dos ecossistemas costeiros da Mata Atlântica, representados pela restinga e o manguezal. Para tanto, foram promovidas pesquisas com uso dos smartphones e de diferentes fontes de papel (enciclopédias, livros didáticos e paradidáticos, etc.).

Ainda nesta etapa, os alunos foram orientados a proceder ao download do aplicativo denominado Map of Life $^{3}$, disponível gratuitamente para smartphones. A partir deste software, foi possível acessar informações atualizadas e específicas sobre a biodiversidade vegetal e animal encontrados nos ecossistemas de manguezal e de restinga da região.

${ }^{3}$ O Map of Life (MOL), é um projeto da Universidade de Yale em parceria com a Nasa, eBird, Google, entre outros que integra fontes diferentes de dados de distribuição das espécies pelo mundo e que podem ser acessadas por um aplicativo de celular. Contém mapas de área de distribuição, pontos de ocorrência e áreas de proteção são fornecidos pela IUCN (União Internacional para a Conservação da Natureza, na sigla em inglês), WWF (Fundo Mundial para a Natureza, na sigla em inglês), GBIF (Sistema Global de Informação sobre a Biodiversidade, na sigla em inglês), além de uma breve descrição sobre algumas das espécies vegetais e animais devidamente catalogados por estas e outras instituições parceiras. É possível a inserção de dados pelos usuários, sob a condição de serem analisados e validados por um conjunto de pesquisadores da Universidade de Yale e os demais parceiros do projeto. 
Figura 01: Capturas de tela do smartphone do aplicativo Map of Life
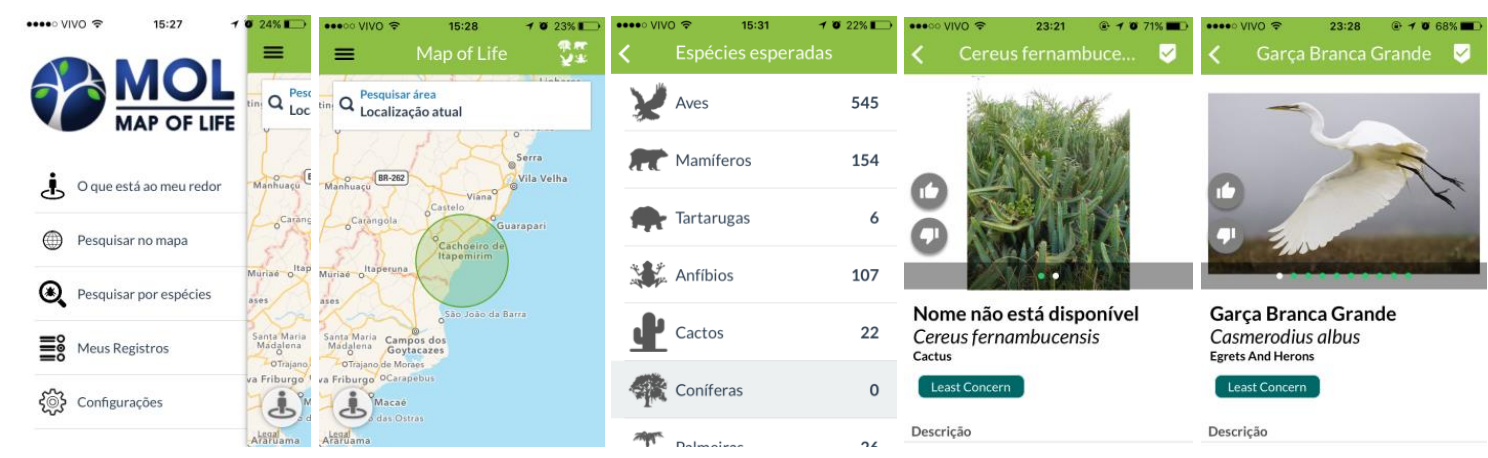

Fonte: Acervo dos autores, 2016

Desafortunadamente, o uso restrito deste aplicativo nos smartphones se deu exclusivamente na residência destes alunos e durante a aula de campo, dada a proibição legal do uso de tecnologias móveis nos ambientes de ensino da rede municipal marataizense, o que nos estimula a debater sobre a inserção de tais recursos tecnológicos em favor dos processos ensino-aprendizagem, especialmente no ensino de Ciências.

Por fim, o terceiro momento descrito por Delizoikov et al. (2002) constitui a etapa de Aplicação do Conhecimento, ocasião em que todas as construções efetuadas nas etapas anteriores se integram e complementam. Assim, mediado por uma aula de campo e fazendo uso dos smartphones para registros audiovisuais e para a identificação dos seres vivos encontrados em campo por meio do aplicativo Map of Life, os alunos tiveram contato com o ambiente natural, mediado pedagogicamente por explicações científicas sobre ambos ecossistemas, além de vivenciarem experiências sensoriais e colaborativas durante o percurso realizado.

Figura 02: Algumas evidências das ações pedagógicas desenvolvidas junto aos alunos do $7^{\circ}$ Ano do Ensino Fundamental
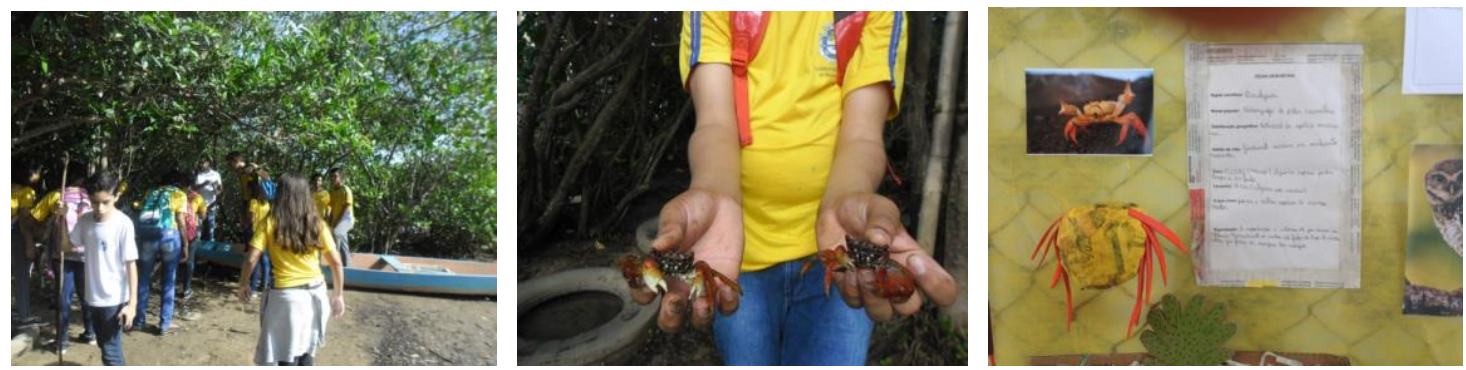

Fonte: Acervo dos autores, 2016. 
Como forma de apresentação das aprendizagens construídas ao longo destes momentos pedagógicos, os alunos utilizaram os seus registros audiovisuais e relatórios da aula de campo e elaboraram vídeos explicativos sobre os ecossistemas visitados, assim como uma ficha descritiva de espécies animais e vegetais encontrados nestes ecossistemas. Inclui-se nessas produções a construção de réplicas em material potencialmente reciclável de alguns dos organismos avistados em campo, acompanhadas de uma ficha descritiva, com suas principais informações biológicas, taxonômicas e de distribuição biogeográfica, além de uma fotografia original feita pelos próprios alunos. Todos esses materiais que foram expostos para a comunidade escolar no evento I Semana do Meio Ambiente, promovido em pelas Secretarias Municipais de Educação e de Meio Ambiente do município de Marataízes.

\section{Considerações Finais}

Atribuir novas possibilidades de aprendizagem socioambiental por meio do uso das TICs em aula de campo constituiu um fator potencializador para a construção do conhecimento em Ciências, especificamente no estudo dos ecossistemas costeiros da Mata Atlântica. Os principais resultados obtidos corroboram com a utilização orientada das tecnologias móveis nos processos educativos, pois permite aos alunos múltiplas formas de acesso a informações antes restritas às exposições orais e demonstrações protagonizadas pelos seus professores e pelo livro didático.

O deslocamento do ensino tradicional para ensino orientado desenvolve a corresponsabilidade na construção de conhecimentos, fato observado durante as atividades desenvolvidas nesta sequência didática. Além disso, o uso do aplicativo Map of Life, contribuiu significativamente para o estudo da biodiversidade ocorrente nos ecossistemas costeiros e suas relações geográficas, culturais, históricas e econômicas, aspectos até então pouco conhecidos pelos estudantes.

Nos processos atuais de construção de conhecimentos, as tecnologias móveis despontam como ferramentas auxiliares para os processos de ensino-aprendizagem, exigindo novos olhares pedagógicos sobre seu uso nos ambientes formais e não formais de ensino, quase sempre restritivos destes valiosos e enriquecedores recursos tecnológicos. 


\section{REFERÊNCIAS}

ALMEIDA, R. R.; ARAÚJO JÚNIOR, C. A. F. O Uso de Dispositivos Móveis no Contexto Educativo: Análise de Teses e Dissertações Nacionais. Revista Tempos e Espaços em Educação, Sergipe, v.11, n.2, p. 25-36, jul. 2003.

COSTA E SILVA, A. P.; CORDEIRO, B. M. P.; SILVA, C. A. As tecnologias digitais chegaram! O que fazer? Formas inovadoras de aprender. In: DANTAS, L. G.; MACHADO, M. J. (Org.). Tecnologias e educação: perspectivas para a gestão, conhecimento e prática docente. 2 ed. São Paulo: FTD, 2014.

DELIZOICOV, D.; ANGOTTI, J. A.; PERNAMBUCO, M. M. Ensino de ciências: fundamentos e métodos. São Paulo: Cortez, 2002.

FLICK, U. Introdução à pesquisa qualitativa. 3. ed. Porto Alegre. Artmed. 2009.

GIL, A. C. Métodos e técnicas de pesquisa social. 5.ed. São Paulo: Atlas, 1999.

GOHN, M. G. Educação não formal e o educador social. Atuação no desenvolvimento de projetos sociais. São Paulo: Cortez, 2010.

GROSSI, M. G. R.; FERNANDES, L. C. B. E. Educação e tecnologia: o telefone celular como recurso de aprendizagem. EccoS - Revista Científica, São Paulo, n. 35, p. 47-65, set./dez. 2014.

JACOBUCCI, D. F. C. Contribuições dos espaços não formais de educação para a formação da cultura científica. Em Extensão: Uberlândia, v. 7, p. 55-66, 2008.

LUCENA, S. Culturas digitais e tecnologias móveis na educação. Educar em Revista, Curitiba, Brasil, n. 59, p. 277-290, jan./mar. 2016

OLIVEIRA, A. P. L.; CORREIA, M. D. Aula de campo como mecanismo facilitador do ensino-aprendizagem sobre os ecossistemas recifais em Alagoas. Revista de Educação em Ciência e Tecnologia: ALEXANDRIA, v.6. n.2, p. 163-190, 2013.

SENICIATO, T.; CAVASSAN, O. Aulas de campo em ambientes naturais e aprendizagem em ciências - um estudo com alunos do ensino fundamental. Revista Ciência \& Educação, v.10, n.1, p. 133 -147, 2004.

SILVEIRA, R. M. P.; CRESTANI, D. M.; FRICK, E. C. L. Aula de campo como prática pedagógica no ensino de geografia para o ensino fundamental: proposta metodológica e estudo de caso. Revista Brasileira de Educação em Geografia, v. 4, n. 7, p. 125-142, Campinas, 2014.

UNESCO. O Futuro da aprendizagem móvel: implicações para planejadores e gestores de políticas. Brasília: UNESCO, 2014a. 


\section{Como referenciar este artigo}

SANTANA, Raíza Carla Mattos et al. O uso de tecnologias móveis no ensino de ciências: uma experiência sobre o estudo dos ecossistemas costeiros da mata atlântica sul capixaba. Revista Ibero-Americana de Estudos em Educação, Araraquara, v. 11, n. 4 p. 2234-2244, 2016. Disponível em: <http://dx.doi.org/10.21723/riaee.v11.n4.9122>. E-ISSN: 1982-5587.

Submetido em: dezembro/2016

Aprovação final em: dezembro/2016 